\title{
MODELING ALGORITHM OF ESTIMATION OF RENAL FUNCTION BY THE COCKCROFT AND MDRD FORMULAS
}

\author{
Boumediene Selma $^{1}$, Samira Chouraqui ${ }^{2}$, Ahmed GHALI $^{3}$ \\ ${ }^{1}$ Department of Computer Science, Faculty of Science. University of Science and \\ Technology "Mohamed Boudiaf" USTO Oran. 31000, Algeria \\ selma.boumedienedyahoo.fr \\ ${ }^{2}$ Department of Computer Science, Faculty of Science. University of Science and \\ Technology "Mohamed Boudiaf" USTO Oran. 31000, Algeria \\ s_chouraquidyahoo.fr \\ ${ }^{2}$ Department of Computer Science, Faculty of Science. University of Science and \\ Technology "Mohamed Boudiaf" USTO Oran. 31000, Algeria \\ ahmed.gh@hotmail.fr
}

\begin{abstract}
The purpose of this study was to determine the concordance between two equations used for estimating glomerular filtration rate, in order to verify the possibility to be used interchangeably in the clinical practice. The two equations are of Cockcroft \& Gault (CG) (1976) formula and MDRD (modification of Diet in Renal Disease) (1999) formula, these two models allow the assessment of glomerular filtration rate $(G F R)$ by calculating creatinine clearance $\left(C L_{C R}\right)$.To make a comparison between these two formulas different models were examined for Subjects with normal renal function, Patients with renal impairment, Diabetic patients, Age and sex, finally lean and obese patients by modeling two algorithms with the two functions. Results show that the formula of Cockcroft \& Gault remains the method of choice for estimating renal function in clinical practice.
\end{abstract}

\section{KEYWORDS}

Cockcroft-Gault formula, MDRD formula, GFR, creatinine, renal function.

\section{INTRODUCTION}

Glomerular filtration rate (GFR) is an important tool for kidney evaluation, in order to detect the early impairment of renal function, to allow correct dosage of drugs cleared by the kidneys or to evaluate patients before transplantation or before using potentially nephrotoxic radiographic contrast media

.For clinical application, the assessment of renal function needs to be accurate, inexpensive and easy to apply. For this reason, in an attempt to find the best method to calculate GFR, a variety of formulas have been developed. 
The use of these formulas is recommended by ANAES and the National Kidney Foundation for the diagnosis of chronic renal disease [1] [2]. Overall, the MDRD formula [3] significantly underestimates GFR "real" about $1 \mathrm{ml} / \mathrm{min} / 1,73 \mathrm{~m}^{2}$, while the CG formula [4] significantly overestimates of about $2 \mathrm{ml} / \mathrm{min} / 1,73 \mathrm{~m}^{2}$ [5].

Much work has been done recently to make the comparison between these two formulas changing in these equations [6] [7] [8] and with different conditions of patients which is relative with GFR [9] [10] [11].

Currently, little information has been published on the performance of the CG and MDRD equations in the elderly (age > 65 years), lean and obese, individuals with liver disease.

The paper is divided in four sections, the fist one is the introduction, secondly cover the recognition chronic kidney disease. Cockcroft \& Gault model and MDRD algorithm are presented in section three. The last one gives Comparison of two algorithms using different cases of patients.

\section{RECOGNITION CHRONIC KIDNEY DISEASE}

Recent recommendations proposed by the research group K / DOQI (Kidney Disease Outcome Quality Initiative) of the National Kidney Foundation and American international occasions by the group KDIGO (Kidney Disease Improving Global Outcomes), have established classification into 5 stages of chronic kidney disease by level of GFR [12], whatever its cause. This classification is associated with an action plan tailored to different clinical stages of kidney disease, the goal is to slow the progression of it and treat its complications [13].

It is therefore necessary to assess the GFR of a patient to use this classification.Creatinine depends also on its rate of production from the muscle creatine, flow is proportional to the mass of striated muscle of the subject: it must always be interpreted in terms of this parameter. Several formulas for estimating GFR have been developed using creatinine and correction factors expected to take into account the interindividual variation in creatinine production by muscle mass [14].

Table 1. Classification of determining the severity of CKD based on the GFR $\left(\mathrm{ml} / \mathrm{min} / 1,73 \mathrm{~m}^{2}\right)$

\begin{tabular}{|c|l|}
\hline stage & \multicolumn{1}{c|}{ description } \\
\hline 1 & Suffering kidney GFR $290+\mathrm{mL} / \mathrm{min} / 1,73 \mathrm{~m}^{2}$ \\
\hline 2 & Suffering kidney GFR $60-89+\mathrm{mL} / \mathrm{min} / 1,73 \mathrm{~m}^{2}$ \\
\hline 3 & GFR $30-59 \mathrm{~mL} / \mathrm{min} / 1,73 \mathrm{~m}^{2}$ \\
\hline 4 & GFR $15-29 \mathrm{~mL} / \mathrm{min} / 1,73 \mathrm{~m}^{2}$ \\
\hline 5 & GFR $<15 \mathrm{~mL} / \mathrm{min} / 1,73 \mathrm{~m}^{2}$ \\
\hline
\end{tabular}

\section{Modeling}

Formula for estimating GFR is only usable for a stable serum creatinine and is not applicable in case of acute variation thereof. The two most commonly used are those of Cockcroft and Gault and the data derived from the study MDRD (Modification of Diet in Renal Disease). These formulas dedicated to the adult population. 


\subsection{Model algorithm of Cockcroft and Gault}

The CG was described in 1976 from 249 men hospitalized. It uses serum creatinine, as well as age, weight and sex of the subject as an indicator of muscle mass [4].

The first algorithm is then written:

Input: Age, weight, creatinine

SYSTEM with the factors related to sex A and F: constants such as;

$\mathrm{A}=1.23$ in men and 1.04 in women.

$\mathrm{F}=1$ in men and 0.85 in women.

If serum creatinine ${ }^{\mu \mathrm{mol}} / L$ then

Clairance $(\mathrm{mL} / \mathrm{min})=\frac{(140-\text { âge }) \mathrm{x} \text { poids }(\mathrm{kg})}{\text { créatininémie }(\mu \mathrm{mol} / \mathrm{L})} * \mathrm{~A}$

Else if serum creatinine $\mathrm{mg} / \mathrm{L}$ then

Clairance $(\mathrm{mL} / \min )=\frac{(140-\text { âge }) \mathrm{x} \text { poids }(\mathrm{kg})}{7,2 * \text { créatininémie }(\mathrm{mg} / \mathrm{L})} * \mathrm{~F}$

End if

Output: the creatinine clearance $\left(\mathrm{CL}_{\mathrm{CR}}\right)$.

This formula estimates GFR not, but the renal clearance of creatinine $\mathrm{mL} / \mathrm{min}$. This is higher than the GFR because creatinine is not only filtered by the glomeruli but also secreted by the renal tubules, and this proportion especially as renal function is impaired. Its advantage is its ease of calculation, but it has several limitations: it overestimates GFR in obese subjects, very thin or edematous, and underestimated in the elderly. Indeed, age and weight are not good indicators of muscle mass in these situations. Finally, it tends to underestimate the functional value of the patients with normal renal function.

- It is currently recommended to estimate renal function in daily practice by a formula using creatinine.

- This estimate only applies to a steady state of creatinine.

- The MDRD formula showed an overall performance.

\subsection{Model algorithm MDRD}

MDRD formula has been described as in 1999 from 1628 patients with chronic kidney disease. In its latest version, published in 2006 [15], it uses serum creatinine, as well as age, sex and ethnicity for African-Americans as indicators of muscle mass. In an effort to standardize assays, whose variability has recently been recognized as significant cause errors of estimate GFR, serum creatinine measured by the laboratory must be standardized in relation to mass spectrometry to be used in the formula. This normalization is gradual implementation in laboratories, as was done a few years ago. 
The second algorithm is then written:

Input: Age, weight, creatinine

SYSTEM with a factor related to sex A and ethnicity factor S: constants such as;

$\mathrm{A}=1 \mathrm{in}$ men and 0.742 in women.

$\mathrm{S}=1.210$ if African American subject.

If serum creatinine $\mathrm{mg} / \mathrm{L}$ then

$\mathrm{DFG}=175 *(\text { créatininémie }[\mathrm{mg} / \mathrm{dl}])^{-1,154} *$ âge $\mathrm{e}^{-0,203} * 0,742 * \mathrm{~A} * \mathrm{~S}$

I

Else if serum creatinine $\mu \mathrm{mol} / \mathrm{L}$ then

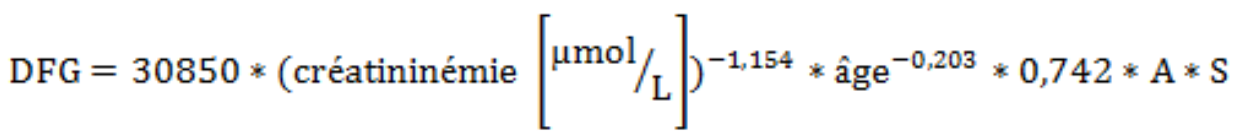

\section{End if}

End if

Output: the glomerular filtration rate (GFR).

End

This formula estimates GFR in $\mathrm{mL} / \mathrm{min} / 1,73 \mathrm{~m}^{2}$. Its performance is good in the elderly and obese. Its boundaries are an overestimation of GFR in patients very thin, and a tendency to underestimate in healthy subjects. There is however no systematic bias related to patient age [5].

\section{COMPARISON OF TWO ALGORITHMS}

4.1. Subjects with normal renal function: there is no significant difference between CG and MDRD formulas [5], [16] despite the difference may seem large in absolute terms.

Table 2. Difference between CG and MDRD in subjects with normal renal function.

\begin{tabular}{|c|c|c|c|c|}
\hline GFR gap "true" & \multicolumn{2}{|c|}{ MDRD } & \multicolumn{2}{c|}{ CG } \\
\cline { 2 - 5 }$\left(\mathbf{m l} / \mathbf{m i n} / \mathbf{1}, \mathbf{7 3 m} \mathbf{m}^{2}\right)$ & {$[5]$} & {$[16]$} & {$[5]$} & {$[16]$} \\
\cline { 2 - 5 } & $-6,2$ & -9 & $-0,3$ & $+1,9$ \\
\hline
\end{tabular}

4.2. Patients with renal impairment: The MDRD allow a better estimate of GFR than the CG formula.

Table 3. Difference between CG and MDRD in Patients with renal impairment

\begin{tabular}{|c|c|c|c|c|}
\hline GFR gap "true" & \multicolumn{2}{|c|}{ MDRD } & \multicolumn{2}{c|}{ CG } \\
\cline { 2 - 5 }$\left(\mathbf{m l} / \mathbf{m i n} / \mathbf{1 , 7 3 \mathbf { m } ^ { 2 } )}\right.$ & {$[5]$} & {$[16]$} & {$[5]$} & {$[16]$} \\
\hline$>\mathbf{6 0}$ & $-0,8$ & $-3,5$ & $+0,9$ & $+7,9$ \\
\hline $\mathbf{3 0 - 6 0}$ & $+0,6$ & $-1,6$ & $+2,6$ & $+4,5$ \\
\hline $\mathbf{1 5 - 3 0}$ & $+2,3$ & $-0,2$ & $+4,9$ & $+2,9$ \\
\hline$<\mathbf{1 5}$ & $+2,4$ & & $+5,2$ & \\
\hline
\end{tabular}


Moreover, the classification of patients according to the severity of their renal failure was more accurate with the MDRD formula: respectively 29.2 and 32.4\% of patients were misclassified when renal function was estimated with the MDRD formula or CG [5].

4.3. Diabetic patients: patients with and without diabetes, the MDRD GFR is closer to "true" that the CG formula [16].

Table 3. Difference between CG and MDRD in patients with and without diabetes.

\begin{tabular}{|c|c|c|}
\hline $\begin{array}{c}\text { GFR gap "true" } \\
\left(\mathbf{m l} / \mathbf{m i n} / \mathbf{1}, \mathbf{7 3} \mathbf{m}^{2}\right)\end{array}$ & MDRD & CG \\
\hline Diabetics & $-0,2$ & $+4,2$ \\
\hline Nondiabetic & $-0,9$ & $+3,1$ \\
\hline
\end{tabular}

4.4. Age and sex [5]: in humans, the MDRD formula is better than the CG. In women, the CG formula may be better in some cases.

Table 4. Difference between CG and MDRD in Age and sex.

\begin{tabular}{|c|c|c|c|c|c|}
\hline \multirow{2}{*}{\multicolumn{2}{|c|}{$\begin{array}{l}\text { GFR gap "true" } \\
\left(\mathrm{ml} / \mathrm{min} / \mathbf{1}, \mathbf{7 3 \mathrm { m } ^ { 2 } )}\right.\end{array}$}} & \multicolumn{2}{|c|}{ MDRD } & \multicolumn{2}{|c|}{ CG } \\
\hline & & \multirow{2}{*}{$\begin{array}{c}\text { H } \\
-5,9\end{array}$} & \multirow{2}{*}{$\begin{array}{c}\mathbf{F} \\
-1,6\end{array}$} & \multirow{2}{*}{$\begin{array}{c}\mathbf{H} \\
- \\
14,5\end{array}$} & \multirow{2}{*}{$\begin{array}{c}\mathbf{F} \\
- \\
10,7\end{array}$} \\
\hline GFR $\searrow 60$ & $\Varangle 55$ ans & & & & \\
\hline & $<65$ ans & $-0,6$ & $-6,1$ & $+3,2$ & $+2,5$ \\
\hline \multirow[t]{2}{*}{ GFR $<60$} & $ð 5$ ans & $+0,5$ & $+1,2$ & $-2,3$ & $-0,1$ \\
\hline & $<65$ ans & $+1,4$ & $+2,3$ & $\begin{array}{r}+5,9 \\
\end{array}$ & $+8,7$ \\
\hline
\end{tabular}

4.5. Lean and obese patients [5]: patients, men and women, thin, with a normal BMI or overweight, the CG formula is better than the MDRD formula. The opposite result was observed in obese patients.

Table 4. Difference between CG and MDRD in Lean and obese patients

\begin{tabular}{|c|c|c|c|c|}
\hline $\begin{array}{c}\text { GFR gap "true" } \\
\left(\mathbf{m l} / \mathbf{m i n} / \mathbf{1 , 7 3 m ^ { 2 }}\right)\end{array}$ & \multicolumn{2}{|c|}{ MDRD } & \multicolumn{2}{c|}{ CG } \\
\cline { 2 - 5 } & $\mathbf{H}$ & $\mathbf{F}$ & $\mathbf{H}$ & $\mathbf{F}$ \\
\hline $\mathbf{B M I}<\mathbf{1 8 , 5}$ & $+12,1$ & $+12,3$ & $+5,1$ & $+7,4$ \\
\hline $\mathbf{1 8 , 5}<\mathbf{B M I}<\mathbf{2 5}$ & $+2,1$ & $-4,1$ & $+1,0$ & $-2,0$ \\
\hline $\mathbf{2 5}<\mathbf{B M I}<\mathbf{3 0}$ & $-2,7$ & $-1,8$ & $+0,4$ & $+5,0$ \\
\hline BMI $>\mathbf{3 0}$ & $-2,8$ & $-2,4$ & $+5,4$ & $+12,5$ \\
\hline
\end{tabular}

\section{CONCLUSION}

The present study confirms the existence of significant differences between CG and MDRD equations, as a result of our study the MDRD equation is closer to the true GFR than that calculated by Cockcroft \& Gault formula and, hence, more suitable as a surrogate of renal function. In conclusion, our study demonstrates that the differences between the MDRD and CG formula were not only influenced by age, body mass index and serum creatinine but also affected by gender and diabetes. In clinical practice physicians should be aware of these differences and take them into consideration when they estimate renal functions.The MDRD formula systematically underestimates GFR in healthy, overweight subjects, particularly in individuals with increased BMI. 
Health Informatics - An International Journal (HIIJ) Vol.2, No.2, May 2013

\section{REFERENCES}

[1] National Kidney Foundation.K/DOQI clinical practice guidelines for chronickidney disease:evaluation, classification, and stratification. Am J Kidney Dis.2002;39:S1-266.

[2] National Agency for Accreditation and Evaluation in Health. Diagnosis of chronic renal failure in adults. September 2002.

[3] Levey AS, Bosch JP, Lewis JB, Greene T, Rogers N, Roth D. A more accurate method to estimate glomerular filtration rate from serum creatinine: anew prediction equation. Modification of Diet in Renal Disease Study Group.Ann Intern Med. 1999;130:461-70.

[4] COCKCROFT DW, GAULT MH. Prediction of creatinine clearance from serum creatinine. Nephron, $1976 ; 16: 31-41$.

[5] FROISSART M, ROSSERT J, JACQUOT C et al. Predictive performance of the modification of diet in renal disease and Cockcroft-Gault equations for estimating renal function. J Am Soc Nephrol, 2005 ; $16: 763-73$.

[6] Hermsen ED, Maiefski M, Florescu MC, Qiu F, Rupp ME. Comparison of the modification of diet in renal disease and Cockcroft-Gault equations for dosing antimicrobials. Pharmacotherapy 2009;29:649-55.

[7] Melloni C, Peterson ED, Chen AY, et al. Cockcroft-Gault versus modification of diet in renal disease: importance of glomerular filtration rate formula for classification of chronic kidney disease in patients with non-ST-segment elevation acute coronary syndromes. J Am Coll Cardiol 2008;51:991-6.

[8] Moranville MP, Jennings HR. Implications of using modification of diet in renal disease versus Cockcroft-Gault equations for renal dosing adjustments. Am J Health Syst Pharm 2009;66:154-61.

[9] Pai MP. Estimating the glomerular filtration rate in obese adult patients for drug dosing. Adv Chronic Kidney Dis 2010;17: e53-62.

[10] Demirovic JA, Pai AB, Pai MP. Estimation of creatinine clearance in morbidly obese patients. Am J ealth Syst Pharm 2009;66:642-8.

[11] Johnson, David W., Jones, Graham R. D., et Al. Chronic kidney disease and automatic reporting of estimated glomerular filtration rate: new developments and revised recommendations. Medical Journal of Australia, 2012; 197 4: 222-223.

[12] LEVEY AS, CORESH J, GREENE T. Using standardized serum creatinine values in the modification of diet in renal disease study equation for estimating glomerular filtration rate. Ann Intern Med, 2006 ; 145 : 247-54.

[13] LEVEYAS, ECKARDTKU, TSUKAMOTO Yet al. Definition and classification of kidney disease : a position statement from kidney disease : improving global outcomes (KDIGO). Kidney Int, $2005 ; 67$ : 2 089-100.

[14] STEVENSLA, CORESH J, GREENE Tet al.Assessing kidney function - Measured and estimated glomerular filtration rate. N Engl J Med, 2006; 354: 2473-83.

[15] LEVEY AS, CORESH J, GREENE T. Using standardized serum creatinine values in the modification of diet in renal disease study equation for estimating glomerular filtration rate. Ann Intern Med, 2006 ; 145 : 247-54.

[16] Poggio ED, Wang X, Greene T, Van LF, Hall PM.: Performance of the Modification of Diet in Renal Disease and Cockcroft-Gault equations in the estimation of GFR in health and in chronic kidney disease. J Am Soc Nephrol 2005; 16: 459-466. 


\section{AUTHORS}

Boumediene SELMA: Has received his engineer degree in computer science from the university of science of Mostaganem Abdelhamid Ibn Badis (Algeria) and actually is in University of Science and technology USTO of Oran (Algeria); preparing his Magister in systems dynamic attitude estimation and control using evolutionary techniques. His current research interests are in the area of artificial intelligence and mobile robotics, Pattern Recognition, neural networks, neuro-fuzzy, data-mining.

Samira CHOURAUI: Has received her MSc degree in Satellite and Systems Communication from Surrey University $\mathrm{UK}$ and received the $\mathrm{PhD}$ in Applied Mathematics from University of Science and technology of Oran (Algeria). She is currently teaching Numerical Analysis and Systems Dynamics at the University of Oran Mohamed Boudiaf USTO of Oran (Algeria).

Ahmed GHALI: Has received his engineer degree in computer science from the university of science of Mostaganem Abdelhamid Ibn Badis (Algeria) and actually is in University of Science and technology USTO of Oran (Algeria); preparing his Magister in advanced optimization and artificial intelligence. His current research interests are in the area of artificial intelligence, Pattern Recognition, neural networks and data-mining. 